\title{
Bipyrrole boomerangs via Pd-mediated tandem cyclization-oxygenation. Controlling reaction selectivity and electronic properties
}

\author{
Liliia Moshniaha1 ${ }^{1}$, Marika Żyła-Karwowska ${ }^{1}$, Joanna Cybińska ${ }^{1,2}$, Piotr J. Chmielewski ${ }^{1}$, \\ Ludovic Favereau ${ }^{3}$ and Marcin Stępień ${ }^{* 1}$
}

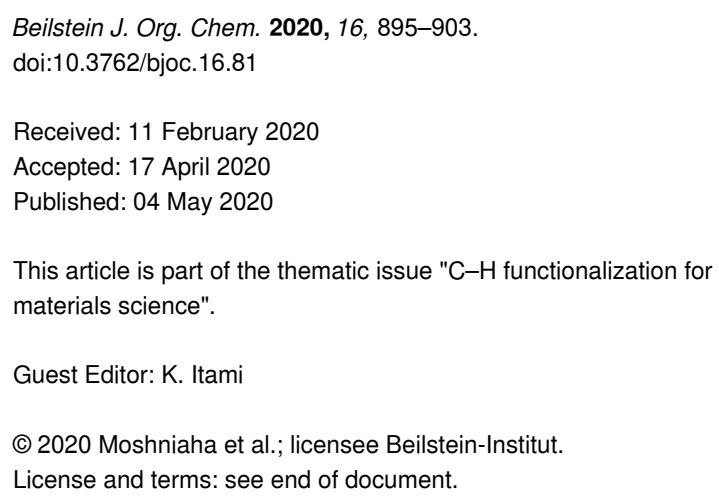

\begin{abstract}
Boomerang-shaped bipyrroles containing donor-acceptor units were obtained through a tandem palladium-mediated reaction consisting of a cyclization step, involving double $\mathrm{C}-\mathrm{H}$ bond activation, and a double $\alpha$-oxygenation. The latter reaction can be partly suppressed for the least reactive systems, providing access to $\alpha$-unsubstituted boomerangs for the first time. These " $\alpha$-free" systems are highly efficient fluorophores, with emission quantum yields exceeding $80 \%$ in toluene. Preliminary measurements show that helicene-like boomerangs may be usable as circularly polarized luminescent materials.
\end{abstract}

\section{Introduction}

Nanographenes and other polycyclic aromatics as well as their heterocyclic analogues are typically obtained by tandem cyclodehydrogenations of oligoaryl precursors [1-3]. This general strategy is attractive because it does not require prefunctionalization of coupling sites and because it provides rapid access to complex $\pi$ systems. Such cyclodehydrogenations can be performed using diverse oxidants [4], with $\mathrm{FeCl}_{3}$ being particularly notable for its versatility, ease of use, and low price [5]. Nevertheless, the synthetic utility of oxidative couplings is often limited by several factors [6]. Consequently, incomplete ring fusion and various side reactions, e.g., chlorination [7], or unexpected rearrangements, are frequently observed [8]. The use of oxidative couplings is further limited for the synthesis of strained $[9,10]$, electron-deficient, or sterically 
congested aromatics [11-14]. Some of these limitations can be overcome by using prefunctionalized precursors [11], as exemplified by reductive Ullmann-type chemistry [15], catalytic direct arylations $[11,14,16,17]$, photoinduced cyclodehydrochlorinations $[18,19]$, or nucleophilic oxidative couplings [20], which may offer milder reaction conditions and superior regioselectivities, at the expense of atom and step economy [21]. The latter disadvantage may be obviated by transitionmetal-mediated double $\mathrm{C}-\mathrm{H}$ bond activation [22,23], which is functionally equivalent to conventional oxidative coupling reactions, and has become a powerful synthetic tool with a rapidly growing scope of use [24-26]. However, in the field of $\pi$-conjugated materials, this strategy has so far remained relatively unexplored [27].

As a part of our ongoing research on $\pi$-extended electron-deficient oligopyrroles [13,28-31], we have recently reported that $\mathrm{Pd}(\mathrm{II})$-mediated double $\mathrm{C}-\mathrm{H}$ activation can be a useful tool for conversion of $1, n$-dipyrrolylalkanes into boomerang-shaped $N, N^{\prime}$-bridged $\alpha, \alpha^{\prime}$-bipyrroles that are not accessible by means of conventional oxidative coupling methods (Scheme 1) [32]. Our approach is applicable to electron-deficient and sterically encumbered systems, notably those based on pyrrole derivatives fused with naphthalenediamide (NDA) and naphthalenemonoimide (NMI) moieties. The double $\mathrm{C}-\mathrm{H}$ bond activation initially used palladium(II) acetate in acetic acid as the coupling system. The subsequent screening revealed, however, that a catalytic coupling could be also achieved in the presence of
silver(I) carbonate as the stoichiometric oxidant. The scope of such $\mathrm{Pd}(\mathrm{II})$-induced couplings was further developed into tandem processes involving consecutive cyclization of substituents $\left(\mathbf{d c T T}^{\mathrm{EE}}\right)$ and oxygenation of pyrrolic $\alpha$-positions to form lactams $\mathbf{\text { CNDA1 }}{ }^{\mathrm{O}}$ and $\mathbf{c N M I 1}{ }^{\mathrm{O}}$. The mechanism of those transformations was subsequently explored using NMR spectroscopy and DFT calculations [33]. In particular, the unprecedented double $\alpha$-oxygenation of bipyrroles was shown to occur through stepwise acetoxylation, which we found to compete with $\alpha-\alpha$ oligomerization. These new bipyrrole boomerangs exhibited enhanced fluorescence with $\Phi_{\mathrm{fl}}$ values of up to $67 \%$, while their bandgaps and chiroptical responses could be tuned by twisting the bipyrrole chromophore. The solvatochromism and apparent superradiance of these chromophores indicated a potential involvement of solvent-induced symmetry-breaking charge transfer in the excited state [34]. Here we report that the above Pd-mediated chemistry is capable of producing highly twisted dilactam boomerangs and provide first examples of $\alpha$-free boomerang systems. These new derivatives are of interest as emitters for both polarized and unpolarized luminescence.

\section{Results and Discussion Synthesis}

The starting 1,n-dipyrrolylalkane precursors $\left(\mathbf{R} n^{\mathrm{H}}, n=2\right.$ or 3$)$ were synthesized by reacting the appropriate pyrrolyl anions with either ethylene ditosylate or 1,3-dibromopropane (Scheme S1, Supporting Information File 1). In our initial coupling experiments, 1,2-dipyrrolylethanes $\left(\mathbf{N D A}^{\mathrm{H}}{ }^{\mathrm{H}}, \mathbf{N M I} 2^{\mathrm{H}}\right)$ and 1,3 -<smiles></smiles>

cNDA1 ${ }^{\mathrm{EE}}$ CNMI1 ${ }^{\mathrm{EE}}$

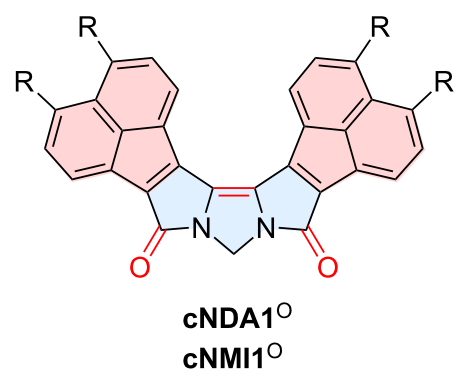<smiles></smiles>

CNDA2 ${ }^{\mathrm{EE}}$ $\mathrm{CNMI2}^{\mathrm{EE}}$<smiles>CCOC(=O)c1c(-c2ccc(C)s2)c2c3n1Cn1c(C(=O)OCC)c(-c4ccc(C)s4)c(c1-3)-c1sc(C)cc1-c1cc(C)sc1-2</smiles>
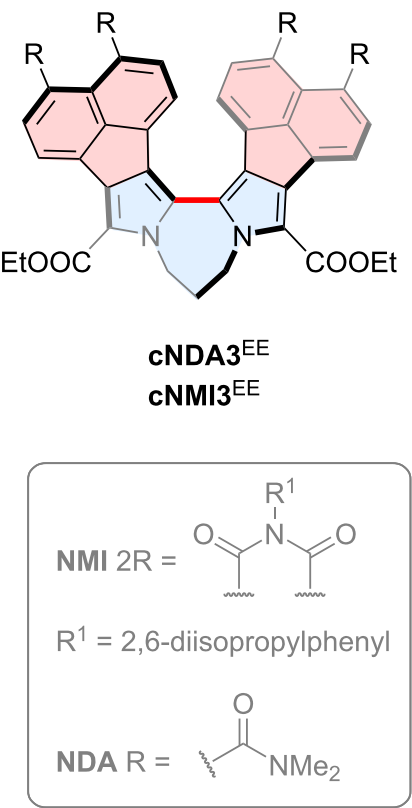
dipyrrolylpropanes $\left(\mathbf{N D A 3}^{\mathrm{H}}, \mathbf{N M I} \mathbf{3}^{\mathrm{H}}\right)$ were reacted with palladium(II) acetate in acetic acid to furnish the expected bipyrrole dilactams in 43-53\% yields (Table 1, entries 1, 6, 11 and 17). Remarkably, it was found that $\mathbf{~} \mathbf{N M I} 2^{\mathrm{O}}$ and $\mathbf{~} \mathbf{N M I 3}{ }^{\mathrm{O}}$ were obtained along with the intermediate $\alpha$-unsubstituted boomerangs, cNMI $^{\mathrm{H}}$ and cNMI3 $^{\mathrm{H}}$, respectively (Scheme 2). Analogous $\alpha$-unsubstituted intermediates $\left(\mathbf{C N D A 2} \mathbf{2}^{\mathrm{H}}\right.$ and $\mathbf{c N D A} \mathbf{3}^{\mathrm{H}}$ ) were not isolated in reactions involving $\mathbf{N D A} 2^{\mathrm{H}}$ and $\mathbf{N D A 3}^{\mathrm{H}}$. The latter behavior is consistent with the selectivity pattern observed previously for $\alpha$-unsubstituted dipyrrolylmethanes NDA $1^{\mathrm{H}}$ and NMI1 $^{\mathrm{H}}$, for which we were only able to isolate the correspond- ing dilactams $\mathbf{c N D A 1} \mathbf{1}^{\mathrm{O}}$ and $\mathbf{c N M I} \mathbf{1}^{\mathrm{O}}$, respectively [32]. Transient formation of $\mathbf{C N D A 1} \mathbf{1}^{\mathrm{H}}$ could, however, be observed in situ for reactions involving NDA1 $^{\mathrm{H}}$ [33].

Subsequent screening revealed that the yield of $\mathbf{c N M I} 2^{\mathrm{H}}$ and cNMI $^{\mathrm{H}}$ could be increased when reactions were performed in more dilute solutions (Table 1, entries 14 and 20). Following our previous experimental and computational findings [32,33], we also checked whether the yields of dilactam products might be improved by increasing the concentration of acetate anions in the reaction mixture. Indeed, annulations of $\mathbf{N D A} n^{\mathrm{H}}$ and<smiles>Cc1cn(CCn2cc(I)c(I)c2)cc1I</smiles>

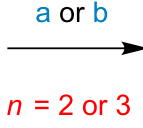

$\mathbf{R} \boldsymbol{n}^{\mathrm{H}}$



$\mathrm{CRn}{ }^{\circ}$

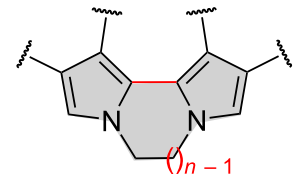

$\mathbf{c R} \boldsymbol{n}^{\mathrm{H}}$

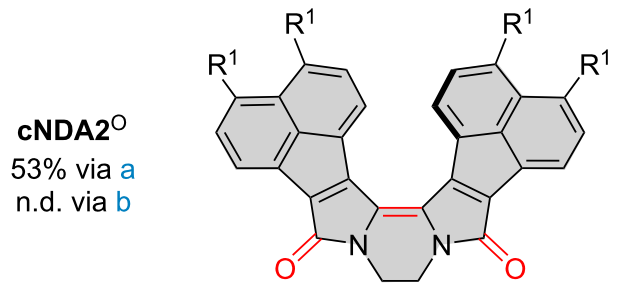

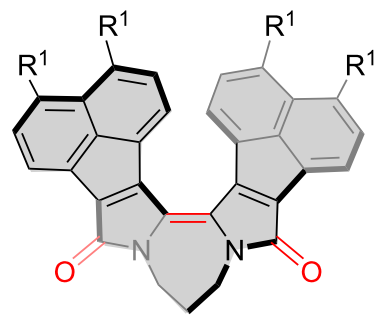

cNDA3 $^{\circ}$

$64 \%$ via a

$18 \%$ via $b$

CNMI2 ${ }^{\circ}$

$60 \%$ via a $14 \%$ via b



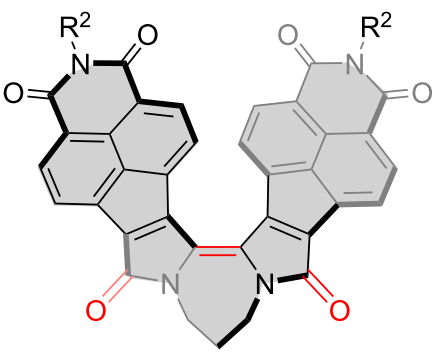

cNMI3 $^{\circ}$

$73 \%$ via a $16 \%$ via $b$

\section{cNMI2 ${ }^{\mathrm{H}}$}

$0 \%$ via a $66 \%$ via b
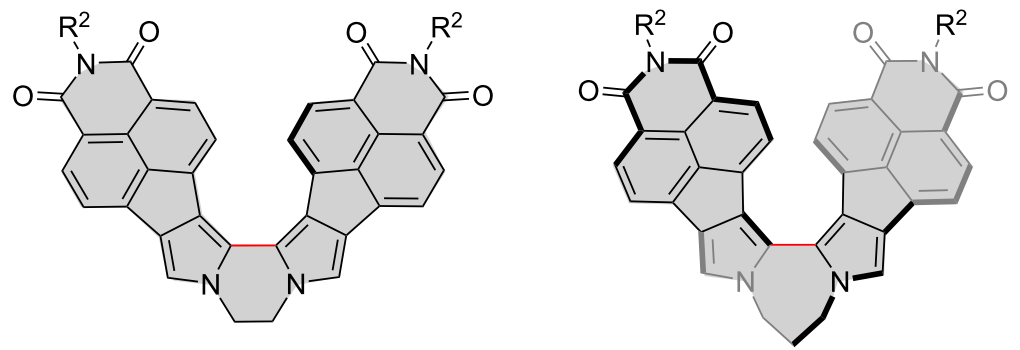

$\mathrm{cNMI}^{\mathrm{H}}$

$0 \%$ via a $41 \%$ via b

$$
\mathrm{R}^{1}=\text { dimethylaminocarbonyl, } \mathrm{R}^{2}=2,6 \text {-diisopropylphenyl }
$$

Scheme 2: Synthesis and structures of $\alpha$-free and $\alpha$-oxygenated bipyrrole boomerangs. Reagents and conditions: (a) $30 \mathrm{mM}$ in $\mathrm{AcOH}, 3 \mathrm{equiv}$ $\mathrm{Pd}(\mathrm{OAc})_{2}, 6$ equiv $\mathrm{KOAc}, 120^{\circ} \mathrm{C}, 1 \mathrm{~h}$; (b) $3 \mathrm{mM}$ in $\mathrm{AcOH}, 3$ equiv $\mathrm{Pd}(\mathrm{OAc})_{2}, 120^{\circ} \mathrm{C}, 1 \mathrm{~h}$. Isolated yields are given for each set of conditions. $M$ enantiomers are depicted for $\mathbf{\mathbf { N D A }} \mathbf{3}^{\mathrm{O}}, \mathbf{\mathbf { c N M I }} \mathbf{3}^{\mathrm{O}}, \mathbf{\mathbf { c N M I }} \mathbf{3}^{\mathrm{H}}$. n.d. $=$ not determined. 


\begin{tabular}{|c|c|c|c|c|c|c|}
\hline entry & reactant & $c[\mathrm{mM}]^{\mathrm{b}}$ & $\mathrm{Pd}(\mathrm{OAc})_{2}{ }^{\mathrm{c}}$ & additive $^{d}$ & $\mathbf{c R} \boldsymbol{n}^{\mathrm{O}}[\%]^{\mathrm{e}}$ & $\mathbf{c} \boldsymbol{R n}^{\mathrm{H}}[\%]^{\mathrm{e}}$ \\
\hline 1 & $\mathrm{NDA}^{\mathrm{H}}$ & 30 & 3 & none & 46 & 0 \\
\hline 2 & $\mathrm{NDA}^{\mathrm{H}}$ & 30 & 3 & KOAC & 53 & 0 \\
\hline 3 & $\mathrm{NDA}^{\mathrm{H}}$ & 30 & 1 & $\mathrm{Ag}_{2} \mathrm{CO}_{3}$ & 34 & 0 \\
\hline 4 & $\mathrm{NDA} 2^{\mathrm{H}}$ & 3 & 3 & none & n.d..$^{f}$ & 0 \\
\hline 5 & $\mathrm{NDA}^{\mathrm{H}}$ & 3 & 3 & KOAc & n.d. ${ }^{f}$ & 0 \\
\hline 6 & $\mathrm{NDA3}^{\mathrm{H}}$ & 30 & 3 & none & 43 & 0 \\
\hline 7 & $\mathrm{NDA}^{\mathrm{H}}$ & 30 & 3 & KOAc & 64 & 0 \\
\hline 8 & $\mathrm{NDA}^{\mathrm{H}}$ & 30 & 1 & $\mathrm{Ag}_{2} \mathrm{CO}_{3}$ & 37 & 0 \\
\hline 9 & $\mathrm{NDA3}^{\mathrm{H}}$ & 3 & 3 & none & 18 & 0 \\
\hline 10 & $\mathrm{NDA3}^{\mathrm{H}}$ & 3 & 3 & KOAC & 23 & 0 \\
\hline 11 & $\mathrm{NMI} 2^{\mathrm{H}}$ & 30 & 3 & none & 52 & 6 \\
\hline 12 & $\mathrm{NMI} 2^{\mathrm{H}}$ & 30 & 3 & KOAC & 60 & 0 \\
\hline 13 & $\mathrm{NMI} 2^{\mathrm{H}}$ & 30 & 1 & $\mathrm{Ag}_{2} \mathrm{CO}_{3}$ & 43 & 14 \\
\hline 14 & $\mathrm{NMI} 2^{\mathrm{H}}$ & 3 & 3 & none & 14 & 66 \\
\hline 15 & $\mathrm{NMI} 2^{\mathrm{H}}$ & 3 & 3 & KOAC & 32 & 30 \\
\hline 16 & $\mathrm{NMI} 2^{\mathrm{H}}$ & 3 & 0.1 & $\mathrm{Ag}_{2} \mathrm{CO}_{3}$ & $<10 \%$ & $<10 \%$ \\
\hline 17 & $\mathrm{NMI}^{\mathrm{H}}$ & 30 & 3 & none & 56 & 9 \\
\hline 18 & $\mathrm{NMI}^{\mathrm{H}}$ & 30 & 3 & KOAC & 73 & 0 \\
\hline 19 & $\mathrm{NMI}^{\mathrm{H}}$ & 30 & 1 & $\mathrm{Ag}_{2} \mathrm{CO}_{3}$ & 34 & 6 \\
\hline 20 & $\mathrm{NMI}^{\mathrm{H}}$ & 3 & 3 & none & 16 & 41 \\
\hline 21 & $\mathrm{NMI}^{\mathrm{H}}$ & 3 & 3 & KOAc & 15 & 12 \\
\hline 22 & $\mathrm{NMI}^{\mathrm{H}}$ & 3 & 0.1 & $\mathrm{Ag}_{2} \mathrm{CO}_{3}$ & 19 & traces \\
\hline
\end{tabular}

${ }^{a}$ Conditions: acetic acid, $120{ }^{\circ} \mathrm{C}, 1 \mathrm{~h} ;{ }^{b}$ concentration of the starting dipyrrolylalkane $\left(\mathbf{R}{ }^{\mathrm{H}}\right) ;{ }^{\mathrm{c}}\left[\right.$ equiv] ${ }^{\mathrm{d}} \mathrm{KOAc}(6 \mathrm{equiv}), \mathrm{Ag}_{2} \mathrm{CO}_{3}(2 \mathrm{equiv}) ;{ }^{\mathrm{e}}$ isolated yields; ${ }^{\mathrm{f}} \mathrm{n} . \mathrm{d} .=$ not determined. Only traces of $\mathrm{cNDA2}^{\mathrm{O}}$ were present in the crude mixture.

$\mathbf{N M I} n^{\mathrm{H}}$ carried out in the presence of 6 equiv of potassium acetate produced the corresponding dilactams in higher yields (53-73\%) with complete conversion (Table 1, entries 2, 7, 12, and 18 ). Under these conditions, the $\mathbf{c N M I} 2^{\mathrm{H}}$ and $\mathbf{c N M I}^{\mathrm{H}}$ intermediates were not isolated. When the same reactions were, however, performed in higher dilution, the yields decreased and the $\mathbf{c N M I} \boldsymbol{n}^{\mathrm{O}}$ to $\mathbf{c N M I} \boldsymbol{n}^{\mathrm{H}}$ ratio was almost $1: 1$, showing the important role of the dipyrrolylalkane concentration in these transformations (Table 1, entries 15 and 21). Additional experiments carried out on $\mathbf{R} n^{\mathrm{H}}$ precursors revealed that the coupling and $\alpha$-oxygenation can also be achieved with 1 equiv of $\mathrm{Pd}(\mathrm{OAc})_{2}$ in the presence of 2 equiv of silver carbonate. Nevertheless, $\mathrm{Ag}_{2} \mathrm{CO}_{3}$ oxidation provided lower yields and the efficiency of this variant was dramatically diminished when the loading of palladium(II) acetate was decreased below 1 equiv (Table 1, entries 16 and 22).

\section{Structure}

The identity of the $\alpha$-oxygenated products, $\mathbf{c R} \boldsymbol{n}^{\mathrm{O}}$, was determined on the basis of high-resolution mass spectrometry and ${ }^{1} \mathrm{H}$ and ${ }^{13} \mathrm{C}$ NMR data. In particular, the ${ }^{1} \mathrm{H}$ NMR spectrum of cNMI $2^{\mathrm{O}}$ revealed the absence of the pyrrolic $\alpha-\mathrm{H}$ resonances, whereas the endocyclic $\mathrm{CH}_{2}$ moiety yielded a pair of very broad peaks at ca. 4.8-3.4 ppm. This splitting, which was also observed for CNDA2 $^{\mathrm{O}}$, is consistent with slow inversion of helicity occurring at the ethylene bridge. In the ${ }^{1} \mathrm{H}$ NMR spectrum of $\mathbf{c N M I} 2^{\mathrm{H}}$, the linker $\mathrm{CH}_{2}$ moiety and the 2,6-diisopropylphenyl (dipp) $\mathrm{CH}$ unit each produced a single broadened signal, indicating that the helix inversion occurs in the fast exchange regime. This apparently faster inversion in $\mathbf{c N M I} 2^{\mathrm{H}}$ than in the $\mathbf{~ C N M I 2} 2^{\mathrm{O}}$ and $\mathbf{~ C N D A 2} 2^{\mathrm{O}}$ lactams correlates with the higher bond order of the $\alpha-\alpha$ linkage in the latter two systems. The chirality of $\mathbf{c N M I}^{\mathrm{H}}$ is reflected in its ${ }^{1} \mathrm{H}$ NMR spectrum, which shows diastereotopic differentiation of $\mathrm{N}-\mathrm{CH}_{2}$ protons of the bridge and the $\mathrm{CH}$ signals of the dipp substituents, consistent with a rigid $C_{2}$-symmetric structure. Analogous diastereotopic effects are observed for $\mathbf{c N D A 3}{ }^{\mathrm{O}}$ and $\mathbf{c N M I 3}{ }^{\mathrm{O}}$. For cNDA3 $^{O}$, the ${ }^{1} \mathrm{H}$ NMR spectrum is additionally complicated by the partially restricted rotation of the $N, N$-dimethylamide substituents in the NDA units. In conjunction with the helicity of the ring system, this restriction leads to effective diastereomerism.

The three-dimensional structures of all boomerangs were modeled using DFT calculations (Figure 1 and Supporting Information File 1). The length of the linker $(n)$ in $\mathbf{c N D A} \boldsymbol{n}^{\mathrm{X}}$ and 


\section{CNDA2 ${ }^{\circ}$}
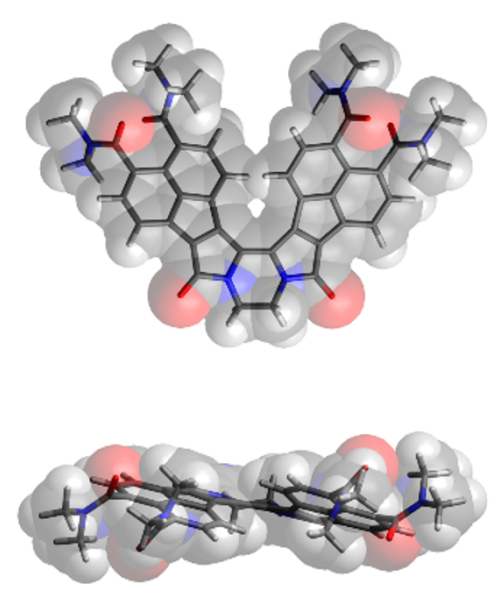

cNMI3 $^{\mathrm{H}}$
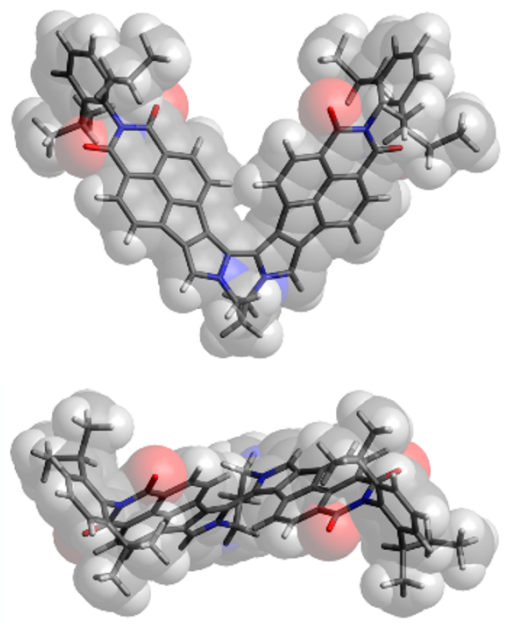

Figure 1: DFT-Optimized structures (B3LYP/6-31G(d,p)) of cNDA2 ${ }^{\mathrm{O}}$ and $\mathrm{cNMI}^{\mathrm{H}}$.

$\mathbf{c N M I n}{ }^{\mathrm{X}}$ controls the in- and out-of-plane geometry of the chromophore. The observed changes can be expressed in terms of two parameters: $\alpha$, the angle between the monopyrrole axis and the $\mathrm{N}-\mathrm{N}$ vector, and $\theta$, the torsion angle between the two monopyrrole axes (Supporting Information File 1, Table S1). In contrast to the previously reported $\mathbf{c R} \mathbf{1}^{\mathrm{O}}$ dilactams, which were nearly planar [32], systems with $n=2$ and 3 are characterized by a twisting distortion, which produces helicene-like conformations. The distortion results from an increased splay angle $\alpha$ between the two pyrrolic subunits, which leads to a greater steric congestion and, consequently, to an increase of the $\theta$ twist.

\section{Electronic properties}

The absorption spectra of the $\mathbf{c N M I} 2^{\mathrm{O}}$ and $\mathbf{c N M I 3}{ }^{\mathrm{O}}$ bipyrroles, recorded in dichloromethane, are red-shifted by respectively 74 and $86 \mathrm{~nm}$ relative to their $\mathbf{c N D A} \boldsymbol{n}^{\mathrm{O}}$ congeners (Table 2, Figure 2, see also Supporting Information File 1 for more optical data). Within each lactam series, when the bridge length $n$ is increased from 2 to 3 , the lowest-energy band is shifted by ca. $17 \mathrm{~nm}$ to longer wavelengths. Pairs of lactam rings present in $\mathbf{~} \mathbf{N M I} 2^{\mathrm{O}}$ and $\mathbf{~ N M I 3}^{\mathrm{O}}$ form a quinoidal substructure, which produces a very significant bathochromic shift of their lowestenergy absorption bands (up to $176 \mathrm{~nm}$ in toluene) in comparison to the of $\alpha$-unsubstituted analogues. Lactam bipyrroles $\mathbf{c N D A} \boldsymbol{n}^{\mathrm{O}}$ and $\mathbf{c N M I} \boldsymbol{n}^{\mathrm{O}}$ show noticeable solvatochromism which is stronger for $n=2$ and is always negative. In contrast, the solvatochromism of $\alpha$-free boomerangs is positive and even more pronounced. On going from toluene to acetonitrile, the onset of the lowest-energy band of $\mathbf{c N M I} \mathbf{2}^{\mathrm{H}}$ is shifted to longer wavelengths by $25 \mathrm{~nm}$.
The $\mathbf{c N M I} 2^{\mathrm{H}}$ and $\mathbf{c N M I}{ }^{\mathrm{H}}$ bipyrroles are very efficient fluorophores (Table 2), noticeably more emissive than the lactam analogues and the other previously reported boomerangs [32]. Highest fluorescence quantum yields were observed in toluene (83 and $80 \%$, respectively). For comparison, the $\Phi_{\mathrm{fl}}$ values for the lactams $\mathbf{c N M I} 2^{\mathrm{O}}$ and $\mathbf{c N M I 3}{ }^{\mathrm{O}}$ are about $1 \%$. Interestingly, the fluorescence of $\mathbf{c N M I} n^{\mathrm{H}}$ boomerang bipyrroles showed a stronger solvatochromic dependence than observed in their absorption spectra (Figure 2). In the more polar solvents, the emission profiles became significantly red shifted and broadened. At the same time, the fluorescence was only moderately quenched with increasing solvent polarity, and the quantum yields of 64 and $66 \%$ were recorded in acetonitrile for $\mathbf{C N M I}^{\mathrm{H}}$ and $\mathbf{c N M I} 3^{\mathrm{H}}$, respectively.

To explore the chiral properties of the helically distorted boomerangs, the separation of enantiomers was attempted for all of them by means of chiral HPLC with CD detection, leading to enantioenriched samples of some boomerangs. The enantiomers of $\mathbf{c R 2}{ }^{\mathrm{O}}$ were found to racemize very fast, thus it was not possible to separate them. The $\mathbf{c R 3}^{\mathrm{X}}$ systems, which contain a 7-membered ring, showed a remarkably diverse behavior. Enantiomers of $\mathbf{c N M I 3}{ }^{\mathrm{O}}$ could not be separated, presumably because of very rapid racemization. The half-life time of CNDA3 $^{\mathrm{O}}$ enantiomers (ca. $0.54 \mathrm{~min}$ ) was too short to record their $\mathrm{CD}$ spectra, but was long enough for a kinetics study (Supporting Information File 1, Figures S8 and S9). Enantioenriched samples of $\mathbf{c N M I}^{\mathrm{H}}$ were configurationally most stable, showing no loss of their optical activity over the course of several hours in solution. Their CD spectra could be satisfactorily correlated with the TD-DFT data obtained for the 

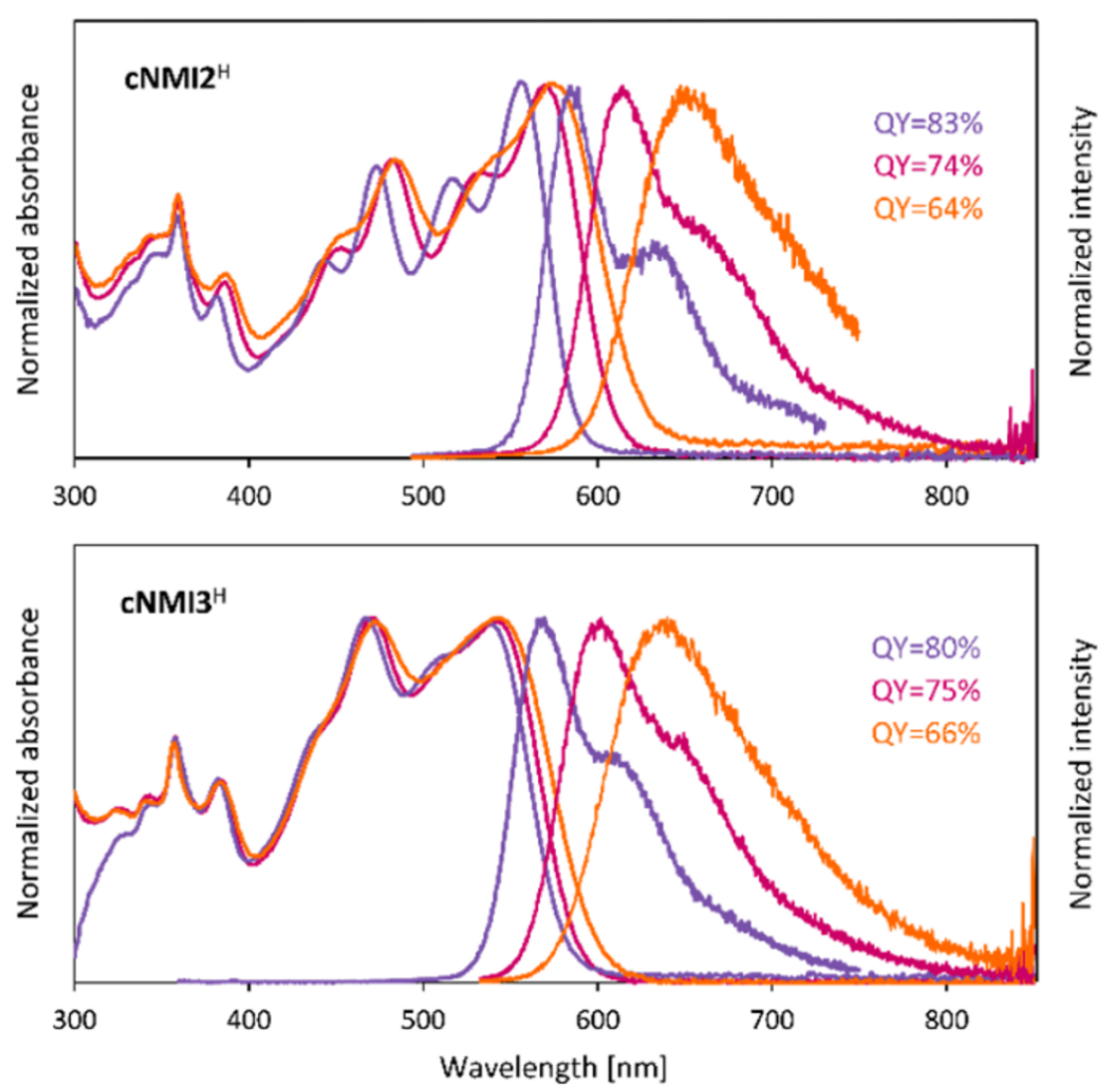

Figure 2: Absorption and emission spectra of $\mathbf{c N M I}^{\mathrm{H}}$ (top) and $\mathrm{cNMI}^{\mathrm{H}}$ (bottom) measured in toluene, dichloromethane and acetonitrile

cNMI3 $^{\mathrm{H}}$ enantiomers (Supporting Information File 1, Figures S5 and S22). Circularly polarized luminescence (CPL) measurements performed for enantioenriched samples of $\mathbf{c N M I 3}^{\mathrm{H}}$ reveled weak signals of opposite signs, with a maximum at ca. $570 \mathrm{~nm}$ consistent with the unpolarized luminescence of this system (Supporting Information File 1, Figure S6). The CPL signals rapidly decayed during the measurements, without any significant loss of the unpolarized emission intensity. This behavior, which precluded a quantitative analysis of the CPL properties, may be attributed to a photoinduced racemization process. The differences in configurational stability of boomerangs are reproduced by DFT calculations, which predict inversion barriers $\Delta G^{\ddagger}, 298$ of 20.0 and $24.7 \mathrm{kcal} / \mathrm{mol}$ for models of $\mathbf{C N D A 3}^{\mathrm{O}}$ and $\mathbf{c N M I 3}{ }^{\mathrm{H}}$, respectively (Supporting Information File 1, Figures S31 and S32). The latter value is consistent with the observed greatest stability of $\mathbf{c N M I} 3^{\mathrm{H}}$.

Frontier molecular orbitals of the boomerangs reveal features characteristic of donor-acceptor systems (Supporting Information File 1, Figures S25-S30). For dilactams, $\mathbf{c} \mathbf{R} \boldsymbol{n}^{\mathrm{O}}$, the HOMO orbital is primarily localized on the dilactam (bipyrrole) moiety, however, with some non-zero amplitudes on the NDA/NMI fragment, whereas the LUMO level encompasses the $\pi$ system more evenly. In the $\mathbf{c N M I} \boldsymbol{n}^{\mathrm{H}}$ series $(n=2,3)$, the HOMO and LUMO are formed by superposition of the corresponding MOs of the monomeric NMI pyrrole (Supporting Information File 1, Figures S23 and S24). However, the LUMO has observably lower amplitudes on the bipyrrole part of the molecule, whereas a more uniform coverage of the $\pi$ system is seen for the HOMO orbital. The experimentally observed bandgap variations and absorption profiles (Table 2 and Table 3, Supporting Information File 1, Figures S1-S4, and S11-S16) were qualitatively reproduced in TD-DFT calculations performed for cNDA2 $^{\mathrm{O}}, \mathbf{c N D A 3}^{\mathrm{O}}$, and $\mathbf{c N M I 3}^{\mathrm{H}}$ (Table 2 and Table 3 , Supporting Information File 1, Tables S2-S4).

The redox properties of the new bipyrrole boomerangs were investigated by means of cyclic (CV) and differential pulse (DPV) voltammetry (Supporting Information File 1, Figures S11-S16). All systems showed at least two reversible one-electron reduction couples and up to two oxidation couples. The first oxidation was reversible for all systems studied except cNMI $2^{\mathrm{H}}$ and cNDA $^{\mathrm{O}}$. The second oxidations were chemically irreversible in all cases and typically produced new irreversible peaks upon the consecutive cathodic scans. In the previously reported $\mathbf{c N M I} \boldsymbol{n}^{\mathrm{EE}}$ series $(n=1,2,3)$ it was also possible to 
Table 2: Experimental and calculated ${ }^{a}$ properties of fused bipyrroles.

\begin{tabular}{|c|c|c|c|c|c|c|c|c|c|}
\hline \multirow[t]{2}{*}{ species } & \multicolumn{3}{|c|}{$\mathrm{MO}$ energies $[\mathrm{eV}]^{\mathrm{a}}$} & \multicolumn{3}{|c|}{$\lambda_{\max }{ }^{a b s}[\mathrm{~nm}]$} & \multicolumn{3}{|c|}{$\lambda_{\max }{ }^{e m}[n m](Q Y)$} \\
\hline & HOMO & LUMO & $\mathrm{HLG}^{\mathrm{b}}$ & tolc & $\mathrm{DCM}^{\mathrm{d}}$ & $\mathrm{MeCN}^{\mathrm{e}}$ & tolc & $\mathrm{DCM}^{\mathrm{d}}$ & $\mathrm{MeCN}^{\mathrm{e}}$ \\
\hline cNDA2 $^{\mathrm{O}}$ & -5.47 & -3.26 & 2.21 & 620 & 610 & 605 & $655(0.07)$ & - & - \\
\hline $\mathrm{cNDA3}^{\mathrm{O}}$ & -5.34 & -3.28 & 2.06 & 636 & 620 & 617 & $694(0.25)$ & - & - \\
\hline $\mathrm{cNMI}^{\mathrm{O}}$ & -5.95 & -4.03 & 1.92 & 693 & 684 & 676 & $738(0.01)$ & - & - \\
\hline $\mathrm{cNMI}^{\mathrm{O}}$ & -5.88 & -4.03 & 1.85 & 711 & 706 & 703 & $768(0.01)$ & - & - \\
\hline $\mathrm{cNMI}^{\mathrm{H}}$ & -5.50 & -2.78 & 2.72 & 555 & 570 & 580 & $575(0.83)$ & $74(0.61)$ & $650(0.64)$ \\
\hline $\mathrm{cNMI}^{\mathrm{H}}$ & -5.56 & -2.73 & 2.83 & 535 & 540 & 546 & $574(0.80)$ & $605(0.75)$ & $655(0.66)$ \\
\hline
\end{tabular}



observe one reversible oxidation and four reductions, the first two being reversible [32]. The first oxidation potentials $\left(E_{\mathrm{Ox} 1}\right)$ vary from 0.62 to $1.09 \mathrm{~V}$, while the first reduction potentials $\left(E_{\mathrm{Red} 1}\right)$ range from -1.54 to $-0.60 \mathrm{~V}$ (Table 3 ). The boomerangs with unsubstituted pyrrole $\alpha$-positions $\left(\mathbf{c N M I}^{\mathrm{H}}\right.$ and $\mathbf{~} \mathbf{N M I} 2^{\mathrm{H}}$ ) are characterized by significantly lower oxidation and reduction potentials than the corresponding dilactam analogues. The electrochemical data obtained for $\mathbf{~ N M I 3}^{\mathrm{O}}$ and cNMI $2^{\mathrm{O}}$ indicate a destabilization of their HOMOs by about $0.5 \mathrm{eV}$ while relative stabilization of the LUMO approaches $1 \mathrm{eV}$ with respect to $\mathbf{c N M I} 3^{\mathrm{H}}$ and $\mathbf{c N M I} \mathbf{2}^{\mathrm{H}}$. This comparably stronger LUMO stabilization in the NMI lactam systems results in a considerable decrease of their electrochemical gap ( $\Delta E$, by ca. $0.5-0.7 \mathrm{~V}$ ), relative to the $\alpha$-free analogues. $\Delta E$ values for lactams $\mathbf{c} \mathbf{R} \boldsymbol{n}^{\mathrm{O}}$ are relatively insensitive to the length of the alkylene linker $n$, in spite of the large changes of the inter-subunit torsion ( $\theta$, Supporting Information File 1, Table $\mathrm{S} 1$ ) caused by the increase of $n$. In line with the absorption spectroscopy data, the $\Delta E$ gap is reduced in the $\mathbf{c N M I}{ }^{\mathrm{O}}$ series by 0.25 to $0.36 \mathrm{~V}$ relative to the corresponding $\mathbf{c N D A} \boldsymbol{n}^{\mathrm{O}}$ analogues. Interestingly, the difference between the first and second reduction potentials in the $\mathbf{c} \mathbf{R} \boldsymbol{n}^{\mathrm{O}}$ dilactams is in the range of 0.25 to $0.33 \mathrm{~V}$, indicat- ing a strong coupling between the subunits. In comparison, this potential difference is much smaller in the $\alpha$-free analogues cNMI3 $^{\mathrm{H}}$ and $\mathbf{c N M I}^{\mathrm{H}}$ (ca. $0.1 \mathrm{~V}$ ).

\section{Conclusion}

The present work shows that the tandem cyclization-oxygenation reaction is a general strategy for the synthesis of lowbandgap bipyrrole boomerangs and is applicable to targets with variable donor-acceptor character and increasing curvature of the bipyrrole linkage. The efficiency of the oxygenation step is dependent on a several of factors, i.e., Pd loading, concentration, and additives. The isolation of unoxygenated products $\mathbf{c N M I} 2^{\mathrm{H}}$ and $\mathbf{c N M I} 3^{\mathrm{H}}$ emphasizes the role of acceptor units and decreased inter-pyrrole coupling in moderating the reactivity of $\alpha$ positions toward oxygenation. The latter systems are of interest because of their very high fluorescence quantum yields, the best so far recorded for this family of fluorophores. Our preliminary results indicate that bipyrrole boomerangs may be usable as CPL emitters, provided that their helicene-like twist is further stabilized against racemization. Efforts to achieve this goal are currently ongoing in our laboratory.

\begin{tabular}{|c|c|c|c|c|c|c|c|}
\hline species & $E_{\text {Red4 }}$ & $E_{\text {Red3 }}$ & $E_{\text {Red2 }}$ & $E_{\text {Red1 } 1}$ & $E_{O \times 1}$ & $E_{\mathrm{Ox2}}$ & $\Delta E^{\mathrm{b}}$ \\
\hline $\mathrm{cNDA}_{1} \mathrm{O}^{\mathrm{C}}$ & $-2.52^{d}$ & $-1.95^{d}$ & -1.36 & -1.03 & $0.88^{d}$ & - & 1.91 \\
\hline cNDA2 $^{\mathrm{O}}$ & - & $-1.82^{d}$ & -1.36 & -1.07 & 0.98 & $1.08^{d}$ & 2.05 \\
\hline cNDA3 $^{O}$ & - & - & -1.31 & -1.03 & $0.89^{d}$ & $1.01^{d}$ & 1.92 \\
\hline $\mathrm{cNMI}_{1} \mathrm{O}_{\mathrm{c}}$ & -1.84 & -1.59 & -0.83 & -0.57 & $1.09^{d}$ & $1.19^{d}$ & 1.66 \\
\hline cNMI2 $^{\mathrm{O}}$ & -1.90 & -1.65 & -0.85 & -0.60 & 1.09 & - & 1.69 \\
\hline $\mathrm{cNMI}^{\circ} \mathrm{O}$ & -1.97 & -1.73 & -0.86 & -0.61 & 1.04 & $1.16^{d}$ & 1.65 \\
\hline $\mathrm{cNMI}_{2}{ }^{\mathrm{H}}$ & - & $-2.46^{d}$ & -1.67 & -1.59 & $0.62^{d}$ & $0.76^{d}$ & 2.21 \\
\hline $\mathrm{cNMI}^{\mathrm{H}}$ & - & -2.54 & -1.80 & -1.70 & 0.68 & $0.98^{d}$ & 2.38 \\
\hline
\end{tabular}

aMeasurements were performed in dichloromethane solution using glassy carbon, platinum rod, and $\mathrm{Ag} / \mathrm{AgCl}$ as working, auxiliary, and pseudoreference electrodes, respectively. All electrode potentials are in volt and are referenced with the ferrocene/ferrocenium couple as the internal standard.

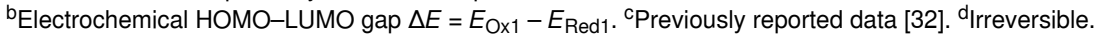




\section{Supporting Information}

\section{Supporting Information File 1}

Synthetic, spectroscopic, and computational details. [https://www.beilstein-journals.org/bjoc/content/ supplementary/1860-5397-16-81-S1.pdf]

\section{Supporting Information File 2}

Cartesian coordinates.

[https://www.beilstein-journals.org/bjoc/content/ supplementary/1860-5397-16-81-S2.zip]

\section{Funding}

Financial support from the National Science Center of Poland (UMO-2017/27/N/ST5/00613 L.M.) and the Foundation for Polish Science (TEAM POIR.04.04.00-00- 5BF1/17-00 M.S.) is gratefully acknowledged. L.F. acknowledges the Ministère de l'Education Nationale, de la Recherche et de la Technologie, the Centre National de la Recherche Scientifique (CNRS), and Rennes Metropole for financial support.

\section{ORCID ${ }^{\circledR}$ iDs}

Liliia Moshniaha - https://orcid.org/0000-0001-9538-178X Marika Żyła-Karwowska - https://orcid.org/0000-0002-4709-9242 Piotr J. Chmielewski - https://orcid.org/0000-0002-2548-6110 Ludovic Favereau - https://orcid.org/0000-0001-7847-2911 Marcin Stępień - https://orcid.org/0000-0002-4670-8093

\section{References}

1. Narita, A. Synthesis of Structurally Defined Nanographene Materials through Oxidative Cyclodehydrogenation. In Synthetic Methods for Conjugated Polymers and Carbon Materials; Leclerc, M.; Morin, J.-F., Eds.; Wiley-VCH: Weinheim, Germany, 2017; pp 183-228. doi:10.1002/9783527695959.ch6

2. Stępień, M.; Gońka, E.; Żyła, M.; Sprutta, N. Chem. Rev. 2017, 117, 3479-3716. doi:10.1021/acs.chemrev.6b00076

3. Wang, X.-Y.; Yao, X.; Narita, A.; Müllen, K. Acc. Chem. Res. 2019, 52, 2491-2505. doi:10.1021/acs.accounts.9b00322

4. Grzybowski, M.; Sadowski, B.; Butenschön, H.; Gryko, D. T. Angew. Chem., Int. Ed. 2020, 59, 2998-3027. doi:10.1002/anie.201904934

5. Sarhan, A. A. O.; Bolm, C. Chem. Soc. Rev. 2009, 38, 2730. doi:10.1039/b906026j

6. Grzybowski, M.; Skonieczny, K.; Butenschön, H.; Gryko, D. T. Angew. Chem., Int. Ed. 2013, 52, 9900-9930. doi:10.1002/anie.201210238

7. Simpson, C. D.; Brand, J. D.; Berresheim, A. J.; Przybilla, L.; Räder, H. J.; Müllen, K. Chem. - Eur. J. 2002, 8, 1424-1429. doi:10.1002/1521-3765(20020315)8:6<1424::aid-chem1424>3.0.co;2-z

8. Ormsby, J. L.; Black, T. D.; Hilton, C. L.; Bharat; King, B. T. Tetrahedron 2008, 64, 11370-11378. doi:10.1016/j.tet.2008.09.105
9. Golling, F. E.; Quernheim, M.; Wagner, M.; Nishiuchi, T.; Müllen, K. Angew. Chem., Int. Ed. 2014, 53, 1525-1528. doi:10.1002/anie.201309104

10. Chen, F.; Tanaka, T.; Osuka, A. Chem. Commun. 2017, 53, 2705-2708. doi:10.1039/c7cc00329c

11. Seifert, S.; Shoyama, K.; Schmidt, D.; Würthner, F. Angew. Chem., Int. Ed. 2016, 55, 6390-6395. doi:10.1002/anie.201601433

12. Zhylitskaya, H.; Stępień, M. Org. Chem. Front. 2018, 5, 2395-2414. doi:10.1039/c8qo00423d

13. Navakouski, M.; Zhylitskaya, H.; Chmielewski, P. J.; Lis, T.; Cybińska, J.; Stępień, M. Angew. Chem., Int. Ed. 2019, 58, 4929-4933. doi:10.1002/anie.201900175

14. Shoyama, K.; Würthner, F. J. Am. Chem. Soc. 2019, 141, 13008-13012. doi:10.1021/jacs.9b06617

15. Myśliwiec, D.; Stępień, M. Angew. Chem., Int. Ed. 2013, 52 , 1713-1717. doi:10.1002/anie.201208547

16. Feng, C.-N.; Hsieh, Y.-C.; Wu, Y.-T. Chem. Rec. 2015, 15, 266-279. doi:10.1002/tcr.201402066

17. Matsuoka, W.; Ito, H.; Itami, K. Angew. Chem., Int. Ed. 2017, 56, 12224-12228. doi:10.1002/anie.201707486

18. Daigle, M.; Picard-Lafond, A.; Soligo, E.; Morin, J.-F. Angew. Chem., Int. Ed. 2016, 55, 2042-2047. doi:10.1002/anie.201509130

19. Morin, J.-F.; Daigle, M.; Desroches, M. Photochemical and Direct C-H Arylation Routes toward Carbon Nanomaterials. In Synthetic Methods for Conjugated Polymers and Carbon Materials; Leclerc, M.; Morin, J.-F., Eds.; Wiley-VCH: Weinheim, Germany, 2017; pp 229-253. doi:10.1002/9783527695959.ch7

20. Ozaki, K.; Kawasumi, K.; Shibata, M.; Ito, H.; Itami, K. Nat. Commun. 2015, 6, 6251. doi:10.1038/ncomms7251

21. Hassan, J.; Sévignon, M.; Gozzi, C.; Schulz, E.; Lemaire, M. Chem. Rev. 2002, 102, 1359-1470. doi:10.1021/cr000664r

22. Åkermark, B.; Eberson, L.; Jonsson, E.; Pettersson, E. J. Org. Chem. 1975, 40, 1365-1367. doi:10.1021/jo00897a048

23. Hellwinkel, D.; Kistenmacher, T. Liebigs Ann. Chem. 1989, 945-949. doi:10.1002/jlac.198919890249

24. Stuart, D. R.; Fagnou, K. Science 2007, 316, 1172-1175. doi:10.1126/science.1141956

25. Yeung, C. S.; Dong, V. M. Chem. Rev. 2011, 111, 1215-1292. doi:10.1021/cr100280d

26. Deng, Y.; Persson, A. K. Å.; Bäckvall, J.-E. Chem. - Eur. J. 2012, 18, 11498-11523. doi:10.1002/chem.201201494

27. Rank, C. K.; Jones, A. W.; Wall, T.; Di Martino-Fumo, P.; Schröck, S.; Gerhards, M.; Patureau, F. W. Chem. Commun. 2019, 55, 13749-13752. doi:10.1039/c9cc05240b

28. Zhylitskaya, H.; Cybińska, J.; Chmielewski, P.; Lis, T.; Stępień, M. J. Am. Chem. Soc. 2016, 138, 11390-11398. doi:10.1021/jacs.6b07826

29. Żyła-Karwowska, M.; Zhylitskaya, H.; Cybińska, J.; Lis, T.; Chmielewski, P. J.; Stępień, M. Angew. Chem., Int. Ed. 2016, 55, 14658-14662. doi:10.1002/anie.201608400

30. Moshniaha, L.; Żyła-Karwowska, M.; Chmielewski, P. J.; Lis, T.; Cybińska, J.; Gońka, E.; Oschwald, J.; Drewello, T.; Rivero, S. M.; Casado, J.; Stępień, M. J. Am. Chem. Soc. 2020, 142, 3626-3635. doi:10.1021/jacs.9b13942

31. Navakouski, M.; Zhylitskaya, H.; Chmielewski, P. J.; Żyła-Karwowska, M.; Stępień, M. J. Org. Chem. 2020, 85, 187-194. doi:10.1021/acs.joc.9b02556 
32. Żyła-Karwowska, M.; Moshniaha, L.; Hong, Y.; Zhylitskaya, H.; Cybińska, J.; Chmielewski, P. J.; Lis, T.; Kim, D.; Stępień, M. Chem. - Eur. J. 2018, 24, 7525-7530. doi:10.1002/chem.201801199

33. Żyła-Karwowska, M.; Moshniaha, L.; Zhylitskaya, H.; Stępień, M. J. Org. Chem. 2018, 83, 5199-5209. doi:10.1021/acs.joc.8b00630

34. Vauthey, E. ChemPhysChem 2012, 13, 2001-2011. doi:10.1002/cphc.201200106

\section{License and Terms}

This is an Open Access article under the terms of the Creative Commons Attribution License

(http://creativecommons.org/licenses/by/4.0). Please note that the reuse, redistribution and reproduction in particular requires that the authors and source are credited.

The license is subject to the Beilstein Journal of Organic Chemistry terms and conditions:

(https://www.beilstein-journals.org/bjoc)

The definitive version of this article is the electronic one which can be found at: doi:10.3762/bjoc. 16.81 